\title{
UNA ORDENACIÓN ADAPTADA A LA PROTECCIÓN SOCIAL DE LA MATERNIDAD-PATERNIDAD POR SUBROGACIÓN
}

\author{
Amparo M. Molina Martín \\ Profesora de Derecho del Trabajo y de la Seguridad Social \\ Universidad de Granada \\ Email: $\underline{\text { molina@ugr.es }}$
}

\begin{abstract}
RESUMEN: La gestación subrogada viene reclamando un espacio de regulación dentro de nuestro ordenamiento jurídico que parece avanzar hacia su concreción en fechas recientes. En materia de Protección Social de las situaciones de maternidad-paternidad derivadas de ella, que es el objeto de la presente investigación, su ordenación es aún limitada y dimana de fuentes no propiamente normativas. Con todo, en este estudio se construye una suerte de régimen jurídico, sobre la base de dicha ordenación, pero también con atención a elementos distintos dispuestos para otras contingencias del Sistema.
\end{abstract}

PALABRAS CLAVE: Gestación subrogada - maternidad - paternidad - Protección Social

ABSTRACT: The gestation surrogate has been demanding a regulatory space within our legal system that seems to advance towards its concretion in recent times. In terms of Social Protection of maternity-paternity situations arising from it, which is the subject of the present investigation, its management is still limited and derives from sources nor properly normative. However, this study builds a kind of legal regime, based on this arrangement, but also with attention to different elements arranged for other contingencies of the System.

KEY WORDS: Gestation surrogate - maternity - paternity - Social Protection 
ÍNDICE:1.- LA LLEGADA DE LA PROTECCIÓN POR MATERNIDAD-PATERNIDAD POR SUBROGACIÓN AL ORDENAMIENTO JURÍDICO ESPAÑOL; 2.- MARCO REGULATORIO DE LA PROTECCIÓN DE LA MATERNIDAD Y LA PATERNIDAD POR SUBROGACIÓN; 3.LA CONSTRUCCIÓN DE UN NUEVO RÉGIMEN JURÍDICO DE SEGURIDAD SOCIAL PARA LA PROTECCIÓN POR MATERNIDAD-PATERNIDAD; 3.1.- Situación(es) protegida(s); 3.2.Hecho causante; 3.3.- Personas beneficiarias; 3.4.- Condiciones, formales y materiales, generales y excepcionales, para el reconocimiento de la protección; 3.5.- Prestaciones económicas; 3.6.Nacimiento, duración y extinción; 4.- SITUACIONES AÑADIDAS. EFECTOS COLATERALES. PROTECCIONES SUPLEMENTARIAS; 5.- UNA "CONTRAPROPUESTA", A MODO DE CIERRE: PROTEGER POR DEPENDENCIA; BIBLIOGRAFÍA E ÍNDICE JURISPRUDENCIAL

\section{1.- LA LLEGADA DE LA PROTECCIÓN POR MATERNIDAD-PATERNIDAD POR SUBROGACIÓN AL ORDENAMIENTO JURÍDICO ESPAÑOL}

Hacía tiempo que la gestación por subrogación había trascendido la esfera de lo privado, en familias en cuyo seno llegaba a ser un asunto tan íntimo en ocasiones como un secreto, y generado un debate más allá de lo jurídico. Tanto la Administración como la Justicia pusieron coto a su reconocimiento y así en consecuencia se obró a nivel normativo, con lo que cualquier planteamiento en términos de Protección Social estaba más que de más ${ }^{1}{ }^{2}$

Y es que la incorporación al Sistema de la Seguridad Social de la maternidad-paternidad subrogadas carece de objeto si no media su "legalización" en el orden civil. De hecho, una vez se produce tal reconocimiento positivo en términos jurídicos, la habilitación de soluciones prestacionales es un acto insoslayable. Sin embargo, no es así como se viene actuando allá donde se toma este tipo de decisiones, quizás por no considerar lo imperativo -insoslayable, decíamos- de dicha protección ${ }^{3}$. En su lugar ha tenido que ser "a golpe" de litigio, "a fuerza" de recurso, ante instancias administrativas y

\footnotetext{
${ }^{1}$ V.g.: S.T.S.J. País Vasco (Sala de lo Social) de 13 de mayo de 2014 (rec. núm. 749/2014): "Prestación de maternidad. Beneficiarios. Madre subrogante que ha tenido un hijo merced a un convenio de gestación de sustitución. Improcedencia”.

${ }^{2}$ Resumen, el anterior, y resúmenes ulteriores -si disponibles- extraídos de la base de datos del Centro de Documentación Judicial (CENDOJ) disponible en http://www.poderjudicial.es/search/indexAN.jsp (consultas realizadas el 30 de junio de 2017).

${ }^{3}$ Por el momento, la primera y única iniciativa legislativa sobre el particular proviene del Grupo Parlamentario de Ciudadanos en el Congreso de los Diputados (registrada el 27 de junio de 2017).
} 
jurisdiccionales, como algunas familias han propiciado el inicio de la construcción de su régimen jurídico.

Se produce precisamente una circunstancia a considerar que interviene en este estado de cosas: la asimilación, por analogía, de la maternidad-paternidad por subrogación con la biológica, en unas ocasiones, y con las "por adopción, guarda con fines de adopción o acogimiento", en otras, sin que haya, sin embargo, identificación absoluta con ninguna de ellas. No habiendo lugar, así pues, para hacerle una traslación directa de dicho marco normativo, y sin visos tampoco de adopción de una regulación propia, lo que en la práctica hay a disposición es un conjunto impreciso de reglas sin cohesión ni completitud.

Visto lo visto, seguidamente presento una propuesta extensa y sistematizada de ordenación de dicha protección social, incluyendo en ella, y enmendados cuando así creo que procede, los contenidos de las resoluciones mencionadas -que, de hecho, dispongo de manera esquemática y sintética justo a continuación-. Por medio de este ejercicio, además, se pone en cuestión que la protección por maternidad -en sentido amplio, es decir, comprensiva también de la paternidad- haya de seguir estandarizada en el descanso (medio o general) de 16 semanas "y demás" (vid infra, apdo. 5.-, pues en ello profundizo al final del estudio).

\section{2.- MARCO REGULATORIO DE LA PROTECCIÓN DE LA MATERNIDAD Y LA PATERNIDAD POR SUBROGACIÓN}

El estado de la cuestión de la regulación de la protección de Seguridad Social para casos de maternidad-paternidad por subrogación es -a mi modo de ver- un ejemplo palmario de recomposición del esquema normativo "clásico", inclusive del sistema de fuentes. Yo diría por momentos hasta que quiere soslayarse el acto de legislar (legislación por acción, o activa) empleando instrumentos que acaban por producir iguales resultados (legislación pasiva o por remisión). Véase a continuación la naturaleza de las fuentes que componen su marco regulatorio para "ilustrarlo" (demostrarlo) ${ }^{4}$ :

\footnotetext{
${ }^{4}$ Están, en consecuencia, dispuestas según los criterios del orden cronológico ascendente y el tipo o categoría de la fuente.
} 
$\checkmark$ S.T.S.u.d. (Sala de lo Social) de 25 de octubre de 2016 (rec. núm. 3818/2015): "Prestación de maternidad. Maternidad subrogada".

$\checkmark$ S.T.S.J. Islas Canarias - Las Palmas (Sala de lo Social) de 4 de noviembre de 2016 (rec. núm. 741/2016).

$\checkmark$ S.T.S.u.d. (Sala de lo Social) de 16 de noviembre de 2016 (rec. núm. 3146/2014): "Prestación por maternidad, maternidad por subrogación. Hijo inscrito en el Registro del Consulado de España en Los Ángeles. Se estima en interpretación integradora de las normas aplicables a la luz de la sentencia del TEDH 26/6/2014. Voto Particular".

$\checkmark$ S.T.S.u.d. (Sala de lo Social) de 30 de noviembre de 2016 (rec. núm. 1307/2015): "RCUD. Prestación de maternidad. Paternidad monoparental por renuncia expresa de la madre natural, respecto de la cual está fijada la filiación en el Registro Civil consular. No hay contradicción con la STJUE de 18 marzo 2014 (Asunto CD, C-167/12)".

$\checkmark$ S.T.S.u.d. (Sala de lo Social) de 30 de noviembre de 2016 (rec. núm. 3183/2015): "Prestaciones de maternidad. Gestación por sustitución. El actor en su momento solicitó la prestación por paternidad que le fue concedida, pero se le denegó la prestación por maternidad. Se desestima el RCUD $^{5}$ del INSS ${ }^{6}$. Voto particular".

$\checkmark$ S.T.S.u.d. (Sala de lo Social) de 30 de noviembre de 2016 (rec. núm. 3219/2015): "RCUD. Prestación por maternidad, maternidad por subrogación. Actor afiliado al $\operatorname{RETA}^{7}$ y casado con otro varón. Hijos inscritos en el Registro del Consulado de España en Los Ángeles. Se estima. Reitera doctrina. Voto Particular".

$\checkmark$ Consulta 29/2016, de 29 de diciembre (Subdirección General de Ordenación y Asistencia Jurídica del I.N.S.S.) ${ }^{8}$ : Respuesta a una consulta sobre el derecho al subsidio por maternidad previsto en el art. 177 L.G.S.S. ${ }^{9}$ en los supuestos de hijos nacidos por gestación por sustitución con arreglo a la legalidad vigente en un país extranjero.

\footnotetext{
${ }^{5}$ Recurso de Casación en Unificación de Doctrina.

${ }^{6}$ Instituto Nacional de la Seguridad Social.

${ }^{7}$ Régimen Especial de la Seguridad Social para Trabajadores por Cuenta Propia o Autónomos.

${ }^{8}$ Disponible en http://www.seg-social.es/descarga/221035.

${ }^{9}$ Real Decreto Legislativo 8/2015, de 30 de octubre, por el que se aprueba el texto refundido de la Ley General de la Seguridad Social (https://www.boe.es/buscar/act.php?id=BOE-A-2015-11724) (o bien TRLGSS).
} 
$\checkmark$ S.T.S.J. Islas Baleares (Sala de lo Social) de 30 de enero de 2017 (rec. núm. 398/2016).

$\checkmark$ Consulta 4/2017, de 20 de febrero (Subdirección General de Ordenación y Asistencia Jurídica del I.N.S.S.) ${ }^{10}$ : Respuesta a una ampliación de la consulta 29/2016.

Si se utilizaran parámetros también "clásicos" para marcar el dies a quo -permítase la expresión- de la ordenación referida, habría que afirmar de entrada su novedad. No en vano, como se encarga de señalar la última referencia listada, las "pautas de aplicación recogidas en la consulta 29/2016 han de ser tenidas en cuenta para resolver los expedientes que en la fecha de emisión de la primera de las sentencias se encontrasen en trámite en vía administrativa. En el caso de que con anterioridad a esa fecha hubiera sido denegada la prestación por maternidad y la resolución fuera firme en vía administrativa, la posibilidad de atender una eventual solicitud de revisión habrá de tener en cuenta las siguientes instrucciones:

$1^{\text {a }}$. Los efectos de la revisión deben circunscribirse a los fijados en el párrafo segundo del artículo 53.1 del TRLGSS, es decir, dichos efectos se producirán a partir de los tres meses anteriores a la fecha en que el interesado presente la correspondiente solicitud. Ahora bien, se reconocerá el derecho a la prestación siempre que todo o parte del periodo de descanso por maternidad se encuentre incluido dentro de los tres meses anteriores a la fecha de la nueva solicitud de la prestación.

$2^{\text {a }}$. Para poder reconocer el derecho a la prestación por maternidad, además de la concurrencia y acreditación de las circunstancias recogidas en la consulta 29/2016, será necesario que el interesado haya disfrutado de forma efectiva del permiso/descanso por maternidad en los términos establecidos en el RDMA ${ }^{11}$, según sea de aplicación el ET ${ }^{12}$ o el EBEP ${ }^{13}$.

\footnotetext{
${ }^{10}$ Disponible en http://www.seg-social.es/descarga/222600.

${ }^{11}$ Real Decreto 295/2009, de 6 de marzo, por el que se regulan las prestaciones económicas del sistema de la Seguridad Social por maternidad, paternidad, riesgo durante el embarazo y riesgo durante la lactancia natural (https://www.boe.es/buscar/act.php?id=BOE-A-2009-4724).

12 Real Decreto Legislativo 2/2015, de 23 de octubre, por el que se aprueba el texto refundido de la Ley del Estatuto de los Trabajadores (https://www.boe.es/buscar/act.php?id=BOE-A-2015-11430).

${ }^{13}$ Real Decreto Legislativo 5/2015, de 30 de octubre, por el que se aprueba el texto refundido de la Ley del Estatuto Básico del Empleado Público (https://www.boe.es/buscar/act.php?id=BOE-A-2015-11719).
} 
$3^{\text {a }}$. En el supuesto de que el interesado hubiere disfrutado con anterioridad del descanso y subsidio por paternidad, y solicitara la prestación por maternidad, se aplicarán, además de lo previsto en los anteriores apartados, las siguientes instrucciones:

a) Disfrute no compartido del permiso/descanso por maternidad. En el supuesto de que el comitente haya disfrutado del permiso/descanso y subsidio por paternidad, y solicite la prestación correspondiente al descanso por maternidad cuyo disfrute efectivo no haya sido compartido con otro comitente, la percepción del subsidio por paternidad deviene incompatible con el de maternidad. En consecuencia, sólo se reconocerá el derecho a la prestación por maternidad si su importe fuera superior a la cuantía ya percibida en concepto de subsidio por paternidad. En este caso, de la cuantía que corresponda percibir en concepto de prestación por maternidad se deducirá el importe ya percibido en concepto de subsidio por paternidad.

b) Disfrute compartido de permiso/descanso por maternidad. De conformidad con lo previsto en el artículo 23.2 del RDMA, sólo en caso de disfrute compartido de periodos permiso/descanso por maternidad es posible reconocer a un mismo progenitor el derecho a la prestación por maternidad compatible con la de paternidad. En consecuencia, si se cumplen los requisitos establecidos, se reconocerá el derecho a la prestación por maternidad, sin que del importe de la prestación se deduzca la cuantía percibida en concepto de subsidio por paternidad"14.

\footnotetext{
${ }^{14}$ Y amplía la Consulta 4/2017 con lo siguiente: “... otro tratamiento merecen aquellos casos en que el nacimiento mediante gestación por sustitución se hubiera producido antes de que esta Entidad gestora asumiera la jurisprudencia del Tribunal Supremo a que se refiere la consulta 29/16 en los que, por esa razón, no se hubiera reconocido al progenitor comitente, único respecto del que inicialmente se determinó la filiación, derecho a prestación por maternidad por período alguno (ni siquiera en aplicación de la revisión prevista en la instrucción $1^{\text {a }}$ del apartado 4 de la presente consulta). En estos casos, y con carácter excepcional, resultará posible reconocer la prestación por maternidad a la persona que mantenía con el comitente una relación conyugal o análoga, que adopta al menor".
} 


\section{3.- LA CONSTRUCCIÓN DE UN NUEVO RÉGIMEN JURÍDICO DE SEGURIDAD SOCIAL PARA LA PROTECCIÓN POR MATERNIDAD- PATERNIDAD}

No existe aún -y quizás tampoco llegue a haberla- una regulación como tal de la protección por maternidad y paternidad por subrogación, en el sentido de una ordenación normativa típica. No llegue a haberla quizás por su limitada trascendencia social en términos cuantitativos, o por la suficiencia-satisfacción de las soluciones dispuestas por otras fuentes (razones, a la postre, de política jurídica, por programa o por oportunidad). Las fuentes de regulación son la Administración técnica y la jurisprudencia, encontrándonos la tal batería de resoluciones como marco "no normativo" 15 .

\section{1.- Situación(es) protegida(s)}

La existencia de una situación - o de un estado, más bien- de maternidad y/o paternidad es un hecho objetivo que el Derecho entiende que precisa de su intervención cuando, a mi modo de ver, en realidad, resulta incontestable. La maternidad, la paternidad, ambas lo son en sí mismas sin necesidad de "visado jurídico". Lo que del orden normativo se espera -así yo lo entiendo- es la disposición de una red protectora adecuada y suficiente para ambas, sin que ello incluya la puesta en cuestión de su existencia.

La tesis que acaba de plantearse adquiere todo su significado en el marco de la gestación por subrogación, pues de ella se derivan auténticos estados de ser madre y/o padre. No resulta de ayuda, pues, que instancias como el T.J.U.E. postulen ciertamente, dentro del preciso contexto de la Directiva $92 / 85^{16}$, pero también de forma poco matizada- que "ese" permiso de maternidad tiene por objeto proteger la condición biológica de la mujer durante y después del embarazo y asimismo las especiales

\footnotetext{
${ }^{15}$ Entre otros, y como referente, vid HIERRO HIERRO, F. J. "Prestaciones de Seguridad Social y nuevas formas de familia: la jurisprudencia comunitaria sobre la maternidad subrogada", Revista del Ministerio de Empleo y Seguridad Social, núm. 127, 2017, especialmente el apdo. 3, que dedica a "la repercusión de la doctrina del TJUE en los pronunciamientos de la doctrina judicial y jurisprudencial interna".

${ }^{16}$ Directiva 92/85/CEE del Consejo, de 19 de octubre de 1992, relativa a la aplicación de medidas para promover la mejora de la seguridad y de la salud en el trabajo de la trabajadora embarazada, que haya dado a luz o en período de lactancia (http://eur-lex.europa.eu/legalcontent/ES/TXT/?uri=CELEX\%3A31992L0085).
} 
relaciones entre la mujer y su hijo durante el periodo que sigue al embarazo o parto ${ }^{17}$. Esas "especiales relaciones" son, o no son, pero por mor del factor humano y no de su valoración jurídica.

Hoy por hoy, volviendo a la cuestión, en España se dispone la siguiente situación protegida:

“El nacimiento de un hijo por gestación por sustitución en un país extranjero con arreglo a la legalidad de ese país, durante los períodos/permisos de descanso que por tales situaciones se disfruten, por aplicación analógica de lo previsto en el" art. 48.4 E.T. o en el art. $49 \mathrm{EBEP}^{18}$.

Es preciso notar, ahora bien, que sólo se da acogida a la maternidad, quizás por escrúpulo de la Administración a la hora de responder a la Consulta planteada -la referida Consulta 29/2016-. Que igual consideración tenga la paternidad, mutatis mutandis, no parece problemático en modo alguno. De hecho, aunque no esté planteado del mismo modo en la respuesta a la Consulta 4/2017, cabe sobreentender dicha situación protegida ampliada también a la paternidad (añadiendo, así pues, la remisión al art. 48.7 E.T.).

\section{2.- Hecho causante}

El nacimiento del hijo es considerado el hecho causante de la protección correspondiente, sea la de maternidad, sea la de paternidad, y a ello se condiciona su nacimiento e inicio de su disfrute. Vuelvo aquí, por tanto, cuando más adelante analizo el tema en cuestión (en el epígrafe 3.6.- Nacimiento, duración y extinción).

\section{3.- Personas beneficiarias}

Al acudir al marco regulatorio de la protección referida buscando respuesta a esta cuestión de a quién beneficia se da con una referencia en la Consulta 29/2016 que ahora sí -así lo aprecio- podría trasladarse tal cual al cuerpo normativo que acogiera la

\footnotetext{
${ }^{17}$ Sentencia del Tribunal de Justicia (Gran Sala) de 18 de marzo de 2014 (asunto C-363/12) (http://eurlex.europa.eu/legal-content/ES/TXT/?uri=CELEX\%3A62012CA0363).

${ }^{18}$ Apdo. $1^{\circ}$ de la Consulta 29/2016 (cit.).
} 
regulación de la protección por maternidad-paternidad derivadas de gestación por subrogación (quizás podría revisarse el uso del género masculino-femenino en el lenguaje, o bien apuntar su utilización de modo genérico) ${ }^{19}$. Textualmente, será persona beneficiaria...:

“... el progenitor -independientemente de su sexo- que haya disfrutado del descanso o permiso y reúna los requisitos que para el reconocimiento del derecho a este subsidio establece el Real Decreto 295/2009"20.

\section{4.- Condiciones, formales $y$ materiales, generales y excepcionales, para el reconocimiento de la protección}

El hecho de la gestación, y en última instancia el acontecimiento del parto, en la maternidad "tradicional" -por así llamar a la biológica-, han de reflejarse documentalmente por parte de los servicios de salud para cumplir con los requerimientos administrativo-procedimentales, o formales, del Sistema de Protección Social. Gran parte de la dinámica de la acción protectora gira en torno a ello y, por tanto, la condiciona.

En este orden de cosas, la protección que se reconoce para las familias que se constituyen al amparo de gestaciones subrogadas pone como condición general que "se haya practicado la previa inscripción de la filiación del hijo en el Registro civil español" 21 , lo cual se vincula a la preexistencia de una "resolución judicial dictada por el órgano jurisdiccional competente en la que se determina la filiación del nacido a favor del progenitor o progenitores comitentes, se recoge el consentimiento libre y

\footnotetext{
19 Sobre el debate que circunda la "determinación" del ser madre y padre, vid MENÉNDEZ SEBASTIÁN, P. y DE CASTRO MEJUTO, S. J. “¿Mater semper certa est? La maternidad subrogada como situación generadora de derechos laborales. Pautas de urgencia para la solución de un intrincado litigio", Revista General de Derecho del Trabajo y de la Seguridad Social (Iustel), núm. 40, 2015, págs. 71-83.

${ }^{20}$ Nuevamente es literal de la Consulta 29/2017.

${ }^{21}$ Puede encontrarse información de interés respecto de la "inscripción de nacimiento" en sección de "Trámites y gestiones personales" dispuesta por el Ministerio de Justicia del Gobierno de España en http://www.mjusticia.gob.es/cs/Satellite/Portal/es/servicios-ciudadano/tramites-gestionespersonales/inscripcion-nacimiento.
} 
voluntario así como la renuncia expresa a la filiación de la madre gestante y se hace constar que no se ha producido una vulneración del interés superior del menor" ${ }^{22}$.

Estando prevista dicha condición general, ahora bien, no se configura ésta únicamente como acaba de presentarse. Hay previstas otras condiciones excepcionales y aptas para suplir la eventual falta de tal resolución judicial constitutiva de la subrogación en la maternidad-paternidad. Y, en efecto, la Consulta 29/2016 señala sobre el particular que “además de la inscripción de la filiación del hijo en el Registro civil español, a la solicitud del subsidio por maternidad deberán acompañarse preceptivamente los documentos que a continuación se indican:

$\checkmark$ Documento público debidamente legalizado en el que conste la renuncia expresa de la madre biológica al ejercicio de la patria potestad sobre el menor. El interesado debe presentar traducción oficial del citado documento.

$\checkmark$ Salvo que este extremo constara expresamente en el documento público debidamente legalizado en el que conste la renuncia expresa de la madre biológica al ejercicio de la patria potestad sobre el menor, el interesado debe acreditar que dicha renuncia no es contraria al ordenamiento jurídico del país de origen del hijo. Dicha acreditación debe llevase a cabo mediante aseveración o informe de un Notario o Cónsul español o de Diplomático, Cónsul o funcionario competente del país de la legislación que sea aplicable. En caso de aseveración o informe de Diplomático, Cónsul o funcionario competente del país de la legislación que sea”.

Y si bien podría verse en éstas un formulario modelo o instrucciones documentales para cursar la(s) solicitud(es) pertinente(s), acaba por resultar que se da cabida a cierto "margen de apreciación" - ¿discrecionalidad, acaso?- por parte de la Subdirección General de Ordenación Jurídica del I.N.S.S. al quedar convocada expresamente a emitir informe previamente al dictado de la resolución que proceda ${ }^{23}$.

Por otra parte, y no precisamente marginal, es fundamental dejar constancia expresa de que en el presente contexto rigen iguales condiciones materiales que para la maternidad

\footnotetext{
${ }^{22}$ Vid Instrucción de 5 de octubre de 2010, de la Dirección General de los Registros y del Notariado, sobre régimen registral de la filiación de los nacidos mediante gestación por sustitución (https://www.boe.es/diario_boe/txt.php?id=BOE-A-2010-15317).

${ }^{23}$ Cfr. apdo. $2^{\circ}$ in fine de la Consulta 29/2016.
} 
y paternidad disciplinan tanto los arts. 165, 178 y 184 L.G.S.S. como los arts. 5 y 23 R.D. 295/2009. A saber:

$\checkmark$ La "condición general de estar afiliados y en alta o en situación asimilada en algún régimen del sistema de la Seguridad Social” y

$\checkmark$ los siguientes sobre la carencia:

○ Ninguna "para el reconocimiento del derecho al subsidio por maternidad a los trabajadores que tengan menos de 21 años de edad en la fecha del parto o en la fecha de la decisión administrativa o judicial de acogimiento o de la resolución judicial por la que se constituye la adopción”.

- "Si el trabajador tiene cumplidos 21 años de edad y es menor de 26 en la fecha del parto o en la fecha de la decisión administrativa o judicial de acogimiento o de la resolución judicial por la que se constituye la adopción, el periodo mínimo de cotización exigido será de 90 días cotizados dentro de los siete años inmediatamente anteriores al momento de inicio del descanso. Se considerará cumplido el mencionado requisito si, alternativamente, el trabajador acredita 180 días cotizados a lo largo de su vida laboral, con anterioridad a esta última fecha”.

- "Si el trabajador tiene cumplidos 26 años de edad en la fecha del parto o en la fecha de la decisión administrativa o judicial de acogimiento o de la resolución judicial por la que se constituye la adopción, el periodo mínimo de cotización exigido será de 180 días dentro de los siete años inmediatamente anteriores al momento de inicio del descanso. Se considerará cumplido el mencionado requisito si, alternativamente, el trabajador acredita 360 días cotizados a lo largo de su vida laboral, con anterioridad a esta última fecha" (único previsto para la paternidad sin atención a la edad).

Aparte dejo apuntado, por si se diera el caso, que igual extensión procede hacer de la protección no contributiva de los arts. 15 a 21 Real Decreto 295/2009, si bien no me detengo en ello. 


\section{5.- Prestaciones económicas}

Consecuencialmente al reconocimiento de las situaciones de maternidad-paternidad derivadas de gestación subrogada como merecedoras de protección, se prevé la concesión de su respectiva cobertura económica, en forma de subsidio -o subsidios, pues aparte del "contributivo-general", del $100 \%$ de la base reguladora ${ }^{24}$, también ha lugar al "contributivo-especial" por parto múltiple, a partir del segundo, igual al que corresponde percibir por el primero durante un periodo de seis semanas-.

La financiación de esta protección, quede dicho, no plantea problemática o discusión algunas al quedar cubierta por los cauces habituales de la cotización. Digo yo que se trata de algo, si no previsto, sí provisto en los Presupuestos de la Seguridad Social.

\section{6.- Nacimiento, duración y extinción}

El disfrute efectivo de los beneficios de la protección por maternidad-paternidad derivada de gestación subrogada ha de iniciarse, a juicio de la Administración, una vez existe la vida fuera del vientre de alquiler. Según reza en la Consulta 29/2016, "el derecho al subsidio solo corresponderá al periodo de descanso o permiso que se disfrute a partir de la fecha del nacimiento del hijo, sin que sea de aplicación la antelación de cuarto semanas prevista para los supuestos de adopción internacional”. Resultan de ello un par de cuestiones controvertidas sobre las que procede detenerse.

En primer lugar, se da a entender con ello, a mi modo de ver, que en el momento del comienzo del derecho hay una "emancipación" entre el descanso y el subsidio, lo cual se opone a un principio elemental de las prestaciones de esta naturaleza. Así, de hecho, se vinculan el uno y el otro cuando se describen las situaciones protegidas (arts. $177 \mathrm{y}$ 183 L.G.S.S. y 2 y 22 R.D. 295/2009). Aventurar el por qué de tal "tratamiento" sitúa el discurso en un terreno especulativo distante de la reflexión jurídico-crítica. Si la cuestión se encuentra así por un descuido, por un exceso de celo, por un agravio comparativo, o por quién sabe qué motivo, poco aporta -así yo lo creo- a su discernimiento. Mejor reconducirlo en pos de una regulación adecuada a la realidad de las circunstancias que rodean la maternidad-paternidad por subrogación, tal y como se encuentra "legalizada" en la actualidad. Y es por ello, en consecuencia, que protección

\footnotetext{
${ }^{24}$ Para el cálculo de la prestación, vid art. 7 R.D. 295/2009.
} 
social y descanso laboral han de permanecer -defiendo- indisolublemente unidos, además de conservar su naturaleza de derechos de los trabajadores así en términos generales como más específicamente en el marco de los de conciliación.

En segundo lugar -es mi opinión, también, contrariamente al postulado de la Administración- que corresponde reutilizar para las situaciones que nos ocupan parte del régimen jurídico de las producidas por adopciones internacionales. Tal cual se las considera a día de hoy resulta, sin embargo, todo lo contrario: ausencia de adaptación de los contenidos de su ordenación a la realidad del desarrollo de estas "experiencias". No en vano, se priva expresamente de cobertura a cualquier momento anterior al alumbramiento, como en el modo -que, es precisamente, rechazado de plano- en el que se reconoce para los susodichos supuestos de adopción internacional. Para mí es inimaginable, además de contradictorio con la subrogación, que el o los "comitentes" no se encuentren junto al recién nacido -"a su disposición", si se prefiere- para prestarle la atención que corresponde a tamaño grado de dependencia -en términos jurídicopositivos- y en el momento "en que se presente", que como fruto de una maternidad biológica que es puede ser cualquiera -viable desde los 180 días, por norma general-. Que esté, prácticamente, forzándose a la familia, bien a esperar hasta el último momento, bien asumir "a su costa" la espera de su hijo o hija, entra en el terreno de la desconsideración cuanto menos.

En el capítulo, por otro lado, de la duración, ni se aprecian disfunciones ni personalmente considero que haya de haberlas. De tal modo, y sobre la base de los arts. 48.5 ab initio y 48.6 E.T., 49.a) y b) EBEP y los arts. 2 y 3 R.D. 359/2009, podría disponerse que la duración del subsidio por maternidad, cuando sea por gestación subrogada, será de dieciséis semanas ininterrumpidas, ampliables en dos semanas por cada hijo a partir del segundo, y asimismo en el supuesto de discapacidad del hijo, y hasta un máximo de treces semanas en los casos de hospitalización del neonato ${ }^{25}$.

En este punto de la duración existe, por otro lado, el margen de intervención que -aquí también- se pone a disposición de "las parejas" de beneficiarios en el supuesto de que se inclinen por la opción del reparto. Así, cuando el subsidio por maternidad sea compartido, éste se abonará a cada beneficiario durante la parte de los periodos de

\footnotetext{
25 Recuérdese que rigen requerimientos precisos para la admisión de documentos justificativosacreditativos de la situación clínica y el estado de salud.
} 
descanso que haya efectivamente disfrutado, por lo que su percepción podrá efectuarse de forma simultánea o sucesiva (dos progenitores comitentes y, por tanto, dos beneficiarios "en potencia", con el período de descanso distribuido a opción de ambos).

Y finalmente llega el momento de la extinción, que como el nacimiento y la duración ha de quedar vinculado al descanso. Sirva lo reflexionado en líneas anteriores como comentario de las presentes. Ello no obstante, sí que es menester detenerse en las repercusiones que acontecimientos inopinados como el de la muerte pueden provocar. De modo tal, y sobre la base del párr. 1 in fine del art. 48.4 E.T., 49 EBEP y párr. 3 del art. 4 R.D. 359/2009, en el caso de fallecimiento del hijo o hijos fruto de gestación subrogada, la duración de la prestación no se verá reducida, salvo que el o los padres soliciten reincorporarse al puesto de trabajo; y si precisamente se decidieron por la "opción del reparto" del descaso, la parte no consumida por uno de ellos no se acumulará al periodo disfrutado por el otro. Aparte, y ahora sobre la base del párr. 2 del art. 5 R.D. 359/2009, en caso de fallecimiento de uno de los progenitores, y beneficiario, el superviviente podrá hacer suya la parte de descanso no disfrutada con su correspondiente protección.

\section{4.- SITUACIONES AÑADIDAS. EFECTOS COLATERALES. PROTECCIONES SUPLEMENTARIAS}

La revisión exhaustiva de la aplicabilidad de la protección de la situación, de las situaciones, de maternidad-paternidad aconseja tomar en consideración la posibilidad de que la situación sea generadora de derechos relacionados con la/s misma/s como son los riesgos durante el embarazo y durante la lactancia natural -0 el cuidado de menores afectados por cáncer u otra enfermedad grave, o las prestaciones familiares, etc.-. La cuestión es que son independientes ya cuando recaen en una misma persona, cuánto más si recaen en dos diferentes.

Respecto del riesgo durante el embarazo, no ha lugar y sin paliativo alguno, con independencia del sistema normativo de protección social que rija la situación, estando aún la criatura en el vientre materno. El tema encuentra acomodo, principalmente, en lo proclamado por la O.I.T. en su Convenio núm. 183, de 2010, sobre protección de 
maternidad, y de manera significativa de acuerdo con lo establecidos en sus arts. 3 y 5 . Respectivamente:

$\checkmark$ "Todo Miembro, previa consulta con las organizaciones representativas de empleadores y de trabajadores, deberá adoptar las medidas necesarias para garantizar que no se obligue a las mujeres embarazadas o lactantes a desempeñar un trabajo que haya sido determinado por la autoridad competente como perjudicial para su salud o la de su hijo, o respecto del cual se haya establecido mediante evaluación que conlleva un riesgo significativo para la salud de la madre o del hijo".

$\checkmark$ "Sobre la base de la presentación de un certificado médico, se deberá otorgar una licencia, antes o después del período de licencia de maternidad, en caso de enfermedad o si hay complicaciones o riesgo de que se produzcan complicaciones como consecuencia del embarazo o del parto. La naturaleza y la duración máxima de dicha licencia podrán ser estipuladas según lo determinen la legislación y la práctica nacionales".

Bien al contrario, el riesgo durante la lactancia natural sí que ha de ser incorporado al catálogo de situaciones protegidas aunque la maternidad/paternidad sea resultado de gestación por sustitución. Baste con traer a este punto el "acontecimiento" del efectivo amamantamiento del hijo del caso atendido por la S.T.J.U.E. de 18 de marzo de 2014 (cit.) para demostrar su verosimilitud. En consecuencia, conforme al art. 48.8 E.T., 48 EBEP y el art. 49 R.D. 295/2009, en el supuesto de riesgo durante la lactancia natural, en los términos previstos en el art. 26 L.P.R.L., la suspensión del contrato finalizará cuando desaparezca la imposibilidad de la trabajadora de reincorporarse a su puesto anterior o a otro compatible con su estado o, a lo sumo, el día en que el lactante cumpla 9 meses.

Y si, en fin, la maternidad-paternidad por sustitución lo es de un hijo con un cáncer u otra enfermedad grave, o se dan circunstancias generadoras de prestaciones familiares, no parece -yo, al menos, no lo aprecio- que haya de haber adaptación normativa ni mucho menos impedimento aplicativo de sus respectivos regímenes jurídicos. 


\section{5.- UNA "CONTRAPROPUESTA", A MODO DE CIERRE: PROTEGER POR DEPENDENCIA}

El reconocimiento de la protección social de supuestos de maternidad-paternidad derivadas de gestación subrogada es prácticamente un imperativo jurídico desde el momento en que se les concede validez en el orden civil y, por tanto, adquieren el carácter de contingencias asimiladas a la maternidad-paternidad de origen biológico o por adopción o acogimiento etc. La consecución de dicha protección, por obra y protagonismo del I.N.S.S. y del T.S., casi al alimón, se procura remodelando lo dispuesto para tales situaciones protegidas en un intento de que "la misma regulación valga para todo menos para lo que no".

Una opción alternativa, que sí que precisaría ahora bien de un ajuste en profundidad de sus normas de aplicación, sería reconducir la protección al sistema de la dependencia. No en vano, se trata de una solución más flexible y adaptable que la -como antes dijeestandarizada maternidad-paternidad. Lo que planteo, en definitiva es que una vez "se ha salido del paso", se prosiga con un auténtico y riguroso proyecto normativo integrador bajo ese paraguas de la dependencia. ¿Qué es si no una relación paternofilial, y máxime (en grado superior) inmediatamente tras el nacimiento? To be continued 


\section{BIBLIOGRAFÍA E ÍNDICE JURISPRUDENCIAL}

- HIERRO HIERRO, F. J. "Prestaciones de Seguridad Social y nuevas formas de familia: la jurisprudencia comunitaria sobre la maternidad subrogada", Revista del Ministerio de Empleo y Seguridad Social, núm. 127, 2017, especialmente el apdo. 3, que dedica a "la repercusión de la doctrina del TJUE en los pronunciamientos de la doctrina judicial y jurisprudencial interna".

- MENÉNDEZ SEBASTIÁN, P. y DE CASTRO MEJUTO, S. J. “¿Mater semper certa est? La maternidad subrogada como situación generadora de derechos laborales. Pautas de urgencia para la solución de un intrincado litigio", Revista General de Derecho del Trabajo y de la Seguridad Social (Iustel), núm. 40, 2015

- S.T.S.J. País Vasco (Sala de lo Social) de 13 de mayo de 2014 (rec. núm. 749/2014)

- S.T.S.u.d. (Sala de lo Social) de 25 de octubre de 2016 (rec. núm. 3818/2015)

- S.T.S.J. Islas Canarias - Las Palmas (Sala de lo Social) de 4 de noviembre de 2016

- S.T.S.u.d. (Sala de lo Social) de 16 de noviembre de 2016 (rec. núm. 3146/2014)

- Sentencia del TEDH 26/6/2014

- S.T.S.u.d. (Sala de lo Social) de 30 de noviembre de 2016 (rec. núm. 1307/2015)

- S.T.S.u.d. (Sala de lo Social) de 30 de noviembre de 2016 (rec. núm. 3183/2015)

- S.T.S.u.d. (Sala de lo Social) de 30 de noviembre de 2016 (rec. núm. 3219/2015)

- S.T.S.J. Islas Baleares (Sala de lo Social) de 30 de enero de 2017 (rec. núm. 398/2016) 